\title{
Contribuição das cooperativas de crédito no desenvolvimento da agricultura familiar: o caso da Sulcredi Ouro
}

\author{
Rodrigo André Fernandes ${ }^{1}$ \\ Rafael Ditati ${ }^{2}$ \\ Juglans Aimi Severo ${ }^{3}$ \\ Rodrigo Antônio Tessaro ${ }^{4}$ \\ Augusto Fischer ${ }^{5}$
}

\section{RESUMO}

Este trabalho enfatiza a importância do cooperativismo de crédito para o desenvolvimento rural, tendo como base as linhas de crédito disponibilizadas para a agricultura familiar. O estudo definiu como objetivo a análise da contribuição da cooperativa de crédito Sulcredi no desenvolvimento da agricultura familiar presente na região. Destaca-se o papel das cooperativas como agentes financeiros para o desenvolvimento da agricultura familiar, o cooperativismo de crédito, a intermediação de recursos do PRONAF, o desenvolvimento e o consequente crescimento econômico local, percebendo-se assim a importância do cooperativismo para o desenvolvimento sustentável. Esta condição é percebida por meio dos relatos da história da cooperativa Sulcredi Ouro, seus benefícios, recursos disponibilizados, e também os resultados obtidos que ressaltam a importância que a cooperativa Sulcredi tem no desenvolvimento da agricultura familiar no município de Ouro.

Palavras-chaves: Cooperativismo de crédito, Agricultura Familiar, Desenvolvimento Econômico.

\section{Contribution of credit cooperatives to the development of family farming: the case of Sulcredi Ouro}

\begin{abstract}
This paper emphasizes the importance of credit cooperativism for rural development, based on credit lines made available to family farming. The objective of this study was to analyze the contribution of Sulcredi, a credit cooperative, in the development of family agriculture in the region. The role of cooperatives as financial agents for the development of family agriculture, the credit cooperativism, the intermediation of PRONAF resources, the development and the consequent local economic growth are highlighted, thus realizing the importance of cooperativism for sustainable development. This condition is perceived through the reports of the history of the cooperative Sulcredi Ouro, its benefits, resources made available, and the results obtained that enhance the importance that the cooperative Sulcredi has in the development of family agriculture in the county of Ouro.
\end{abstract}

Key-words: Credit Cooperativism, Family Agriculture, Economic Development.

\footnotetext{
${ }^{1}$ Bacharel em Administração. Especialista em Metodologia do Ensino na Educação Superior. Mestrando em Administração pela Unoesc, linha de pesquisa Competitividade do Agronegócio. Professor e Coordenador do curso de Administração da Unoesc (Capinzal) e Coord. do curso de Tecnologia em Processos Gerenciais - EAD.

${ }^{2}$ Bacharel em Administração pela Universidade do Oeste de Santa Catarina - Unoesc campus de Joaçaba.

${ }^{3}$ Bacharel em Administração. Especialista em Administração de Recursos Humanos (Unoesc) e MBA em Gestão Estratégica (UFPR). Mestrando em Administração pela Unoesc. Professor e pesquisador da Unoesc (Joaçaba e campos novos) Coordenador do Curso de Administração da Unoesc (Campos Novos).

${ }^{4}$ Tecnólogo, graduado em Processos Gerenciais pela Universidade do Oeste de Santa Catarina (Unoesc). PósGraduando do curso de em Engenharia de Produção da Unoesc.

${ }^{5}$ Doutor em Administração (USP). Mestre em Engenharia de Produção e Sistemas (UFSC). Bacharel em Administração (UNC). Professor e Pesquisador da Universidade do Oeste de Santa Catarina (Unoesc) no Mestrado Profissional em Administração, na Linha de Pesquisa Competitividade do Agronegócio.
} 


\section{INTRODUÇÃO}

O cooperativismo de crédito é uma estratégia de desenvolvimento utilizado por pessoas físicas e jurídicas que, por meio do associativismo, passam a fazer suas movimentações financeiras por meio dela, e não mais com os bancos tradicionais.

Por definição, Pinheiro (2007) considera que as cooperativas de crédito são caracterizadas como instituições financeiras constituídas sob a forma de sociedade cooperativa e que tem por objeto a prestação de serviços financeiros aos associados. Dentre os serviços propostos, cita-se exemplos como a concessão de crédito, captação de depósitos à vista e a prazo, fornecimento de cheques, prestação de serviços de cobrança, de custódia, entre outros.

Quando relacionado à agricultura familiar, considera-se que o cooperativismo de crédito desempenha um importante papel na geração de trabalho e renda para a agricultura familiar, pois são inúmeros os projetos que podem ser desenvolvidos a partir da terra e do capital social, contribuindo assim para o desenvolvimento econômico do local.

Sabendo-se que a agricultura familiar é uma forma de produção caracterizada pela predominância da interação entre gestão e trabalho dos membros de uma mesma família no processo produtivo da pequena propriedade rural (LAMARCHE, 1993), desenvolvido em pequenas propriedades e que as cooperativas de crédito atuam no apoio a agricultura familiar, este estudo centra-se em saber "Qual a contribuição da Sulcredi Ouro no desenvolvimento da agricultura familiar na região?”

As cooperativas, de modo geral, exercem função importante na intermediação de recursos dos programas do governo federal junto a seus associados, contribuindo assim para aumentar a produtividade, gerar empregos e melhorar a renda dos agricultores familiares. Sendo assim o objetivo geral deste trabalho define-se em identificar as ações da Sulcredi Ouro no desenvolvimento da agricultura familiar em sua área de atuação.

Apresenta-se também os objetivos específicos: Explorar os conceitos relacionados ao desenvolvimento regional e a produção rural da agricultura familiar na perspectiva histórica do cooperativismo de crédito; Identificar os benefícios propostos pela cooperativa Sulcredi; Quantificar o número de intermediações envolvidas na disponibilização de crédito; Avaliar a destinação dos recursos na propriedade e que são disponibilizados pela cooperativa de crédito rural. 
Para desenvolvimento deste estudo, utilizou-se como metodologia a pesquisa exploratória descritiva, aliada a técnica qualitativa de coleta de dados primários por meio das entrevistas. Também se destaca a revisão bibliográfica, onde são explorados os temas relacionados à agricultura familiar, desenvolvimento econômico e cooperativismo de crédito.

Este trabalho está dividido em cinco tópicos, tendo como primeiro tópico a introdução, composto pela apresentação inicial do tema cooperativismo de crédito, o problema e a justificativa. O segundo tópico de estudo descreve, a partir de literatura direcionada aos temas de estudo, o cooperativismo de crédito, a agricultura familiar e o desenvolvimento econômico, elaborados como forma de subsidiar informações para a fundamentação do trabalho.

No terceiro tópico cita-se de forma mais aprofundada os procedimentos metodológicos, para pesquisa, em que os resultados irão compor o quarto tópico de estudo, composto pela descrição e análise de dados, analisando a importância da cooperativa de crédito Sulcredi Ouro no desenvolvimento da agricultura familiar presente na região.

Por fim, o quinto tópico destaca as considerações finais, abordando os principais resultados obtidos e analisados que se relacionam com os objetivos propostos, seguido pela listagem do material de consulta utilizado para desenvolvimento do estudo.

\section{REVISÃO BIBLIOGRÁFICA}

Segundo Gil (2009 p. 44) pesquisa bibliográfica é desenvolvida com base em material já elaborado, constituído principalmente de livros e artigos científicos, dissertações e teses, publicações utilizadas para a formação da base teórica deste estudo. Neste tópico apresenta-se a revisão aprofundada dos principais pontos temáticos relevantes ao artigo.

\subsection{Cooperativismo de Crédito}

Em um contexto histórico, o Cooperativismo de crédito deu seus primeiros passos em 1847, quando Friedrich Wilhelm Raiffeisen, fundou no povoado de Weyerbusch / Westerwald, atual Alemanha, a primeira associação de apoio para a população rural que, embora não fosse ainda uma cooperativa, serviu de modelo para uma futura atividade cooperativista. Foi em 1864, que Raiffeisen fundou a primeira cooperativa denominada 
Associação de Caixas de Empréstimo de Heddesdorf (Heddesdorfer Darlehnskassenveirein) (PINHEIRO, 2007).

Búrigo (2010), destaca ainda que o modelo Raiffeisen buscava uma forma diferente de comandar os processos, garantindo a participação de pessoas com condições de vida mais inferiores ou mesmo daqueles que não possuíam o hábito da poupança. Recomendava-se a época que as cooperativas de crédito não estabelecessem cotas de entrada muito altas, como forma de otimizar a adesão. Sendo assim, as primeiras cooperativas de crédito não tinham capital considerável.

O início da história do cooperativismo agropecuário no Brasil é marcado por uma estrutura autoritária, na qual os interesses dos agricultores familiares não eram considerados. As iniciativas eram para a produção exportadora. Esse modelo beneficiou os produtores que detinham grandes extensões de terra e privilegiavam a monocultura. Já os pequenos produtores, camponeses e demais agricultores cujas atividades produtivas eram realizadas pela família, se viam cada vez mais marginalizados (PIRES, 2009).

As bases do cooperativismo derivaram de ações que variam desde o uso coletivo do solo (condições impostas pelo ambiente que propiciava a organização coletiva para a sobrevivência) até o exercício da profissão, como as corporações de ofício, que procuravam assegurar posição privilegiada no mercado para seus componentes, defendendo-os contra a concorrência externa. Em ambas as formas de ação cooperativa, os indivíduos se encontravam na ausência de liberdade e independência, pois, no primeiro caso, a relação de subordinação e obediência é que mantinha o indivíduo na organização e, no segundo, apesar da defesa dos profissionais, os mesmos perdiam autonomia em seu trabalho, seguindo as determinações das corporações (FRANKE, 1988). Com o avanço das cooperativas no Brasil, outros serviços e possibilidades foram explorados.

Um destes é o crédito rural, que tem importância como instrumento de política agrícola para o desenvolvimento do país, uma vez que estimula os investimentos rurais. Para Padilha e Medeiros (2004), o crédito rural possibilita a manutenção e a expansão dos padrões de produtividade alcançados pela agricultura brasileira, além de ter se constituído em uma fonte de estímulo à implantação e ao desenvolvimento de uma indústria interna de insumos e equipamentos agrícolas, e a formação de complexos agroindustriais hoje predominantes no país. 
Saron e Hespanhol (2012) afirmam que o crédito contribuiu significativamente para a consolidação de uma nova fase do desenvolvimento agrícola brasileiro por meio da aproximação dos agricultores das políticas de incentivo a estruturação e modernização da propriedade, aumentando consequentemente a produção. O papel do crédito rural é o de gerador de oportunidades, aproximando o beneficiário das políticas que estimulam investimentos em avanços tecnológicos e melhorias nas propriedades. Ainda segundo os autores, o crédito, quando acessado de forma qualificada, promove o crescimento da produção e diversificação das unidades familiares, nos processos de agregação de valor, industrialização e comercialização (SARON; HESPANHOL, 2012).

A disponibilização do crédito configura-se como um fator importante de estímulo ao desenvolvimento rural por possibilitar o investimento em capital fixo e humano e em insumos básicos da atividade rural, o que facilita o processo de produção e inovação, ampliando as relações dos agricultores com o ambiente socioeconômico (PEREIRA et. al, 2006). Ademais, o crédito também traz benefícios não diretamente associados à produção, como permitir a regularização do fluxo de consumo pessoal do produtor por meio da compatibilização de sua renda contínua ou sazonal.

\subsection{Agricultura Familiar}

A agricultura familiar foi reconhecida no Brasil pela sua importância em gerar empregos no campo e por produzir alimentos para suprir as necessidades de consumo da população urbana e para manter os indivíduos no meio rural, tendo assim em sua história um importante papel social, capaz de gerar com o trabalho familiar, o diferencial na produção dos alimentos essenciais para a alimentação da população brasileira.

Segundo Carmo (1998) “[...] a agricultura familiar apresenta uma considerável capacidade para atender a mercados exigentes em termos de diversificação e qualidade devido à possibilidade de flexibilidade da produção e maior intensidade de utilização do fator trabalho.”.

A agricultura familiar surge como conceito e tem sua legitimação perante o Estado em meados dos anos de 1990 com a criação do Programa Nacional de Fortalecimento da Agricultura Familiar - PRONAF (GRISA, 2010). A partir de então, a agricultura familiar passa a ser agenda de diversas discussões das políticas públicas de desenvolvimento rural. 
O termo agricultura familiar é um conceito utilizado para caracterizar as unidades de produção rural, estruturadas no trabalho familiar, que se identificam pela relação entre terra, trabalho e família. As recentes transformações ocorridas no espaço agrário brasileiro, com o advento da modernização, afetaram as pequenas e médias propriedades rurais, provocando a descapitalização e a exclusão social do pequeno agricultor familiar, o que trouxe como resultado o êxodo rural (SCHNEIDER,2003, p. 99).

"A agricultura familiar, atualmente simboliza a geração de empregos no meio rural, sendo a principal forma de atividade econômica de muitas famílias, além disso, contribui com a segurança alimentar, com a questão ambiental, econômica e social" (MENDES; MESQUITA, 2012, p. 18).

Nota-se que a agricultura familiar ocupa um papel importante na sociedade. Além disso, estimula a produção diversificada, amplia a capacidade de consumo de alimentos e de outros bens pelas famílias rurais e absorve a mão-de-obra rural. Assim, afirma-se que essa unidade de produção exerce múltiplas funções estratégicas para a sociedade e isto deve ser reconhecido e traduzido em políticas públicas adequadas, as quais proporcionam a geração de empregos, a melhoria da renda e, consequentemente, a diminuição dos conflitos sociais e do êxodo rural. Alinha-se ao exposto a importância de estimular esta modalidade de produção rural, entre outros meios, pela promoção do crédito, como já explorado.

Neste contexto, a agricultura brasileira desenvolveu alguns componentes que marcaram a organização social do Brasil colônia. Cita-se três principais formas que marcaram este período: "o latifúndio herdado das capitanias hereditárias e das sesmarias, a monocultura de exportação voltado ao atendimento de requisitos econômicos da metrópole portuguesa e o trabalho escravo", além de outras formas mais periféricas de organização como a pecuária extensiva e a produção de gêneros complementares de consumo interno, como a mandioca o milho e o arroz (OLIVEIRA, 2009, p. 2).

Búrigo (2010) considera que a agricultura familiar representa uma atividade de grande importância socioeconômica, determinando um modo de vida e uma alternativa econômica considerada como uma estratégia para a construção de um estilo de desenvolvimento que valorize os preceitos da sustentabilidade. A valorização do modo de vida particular das características e potencialidades econômicas, culturais e sociais da agricultura familiar passa pela reestruturação e qualificação dos serviços financeiros existentes. O agronegócio, em especial promovido pela agricultura familiar, conforme o 
exposto, possibilita a diversificação e o fortalecimento econômico, não só das famílias diretamente relacionadas à atividade produtiva, mas à cadeia produtiva, incluindo-se aqui as cooperativas de crédito rural, e a economia regional e nacional, por consequência.

\subsection{Desenvolvimento Econômico}

Segundo as teorias de crescimento econômico, a agricultura é o primeiro setor a se desenvolver durante o processo de crescimento de um país e que consequentemente permite o crescimento dos demais setores da economia. Assim, sendo o Estado o órgão orientador do processo de crescimento econômico, este se torna o responsável pela realização de políticas públicas direcionadas à agricultura, que por sua vez, contribui para o desenvolvimento dos demais setores produtivos (DIAS; DIAS, 2005).

O processo de desenvolvimento econômico no Brasil pode ser dividido em três períodos principais. O primeiro consiste no período colonial até o início da década de 1930 em que as políticas de crescimento eram orientadas diretamente para a agricultura, pois esta representava o setor dinâmico da economia. Na ausência de industrialização, o setor exportador é responsável pela arrecadação de divisas e pela importação de produtos industrializados.

A formulação de políticas para o desenvolvimento da indústria nacional deu-se com o objetivo de promover a substituição de importações. Assim, economia brasileira entrou em um novo modelo de desenvolvimento, orientado por um planejamento descentralizado em que as alocações dos recursos econômicos eram realizados com base na conduta do mercado (JONES, 2000).

A atividade agropecuária possui relevância em vários aspectos da vida humana. Ela se destaca desde tempos imemoriais do ponto de vista da segurança alimentar e fonte de trabalho, depois como fonte de divisas por meio do comércio e insumos para atividades industriais. A importância da agropecuária é expressa com o destaque de setor primário da economia, a indústria é nomeada como setor secundário e o comércio como setor terciário. Ou seja, as atividades primárias são a origem da geração de riqueza e em muitas ocasiões são o princípio para o desenvolvimento de outras ações econômicas, a agropecuária pode ser uma grande fonte de geração de divisas e de formação de capital (JOHNSTON; MELLOR, 1961), 
caracterizando-se a importância do agronegócio como propulsora da evolução econômica, e seus desdobramentos, para um Estado.

O conceito de Desenvolvimento Sustentável que mais teve difusão é sem dúvida o descrito no relatório Brundtland como "o desenvolvimento que satisfaz as necessidades do presente sem comprometer a capacidade de as futuras gerações satisfazerem suas próprias necessidades" (BRUNDTLAND, 1987). Porém, muitas vezes se confundem os termos crescimento e desenvolvimento econômico ou tratam como se fossem sinônimos. No entanto, cabe destacar essa distinção entre ambos os conceitos.

Segundo Siedenberg (2006), crescimento é um processo de mudanças de caráter predominantemente quantitativo, significando aumento em dimensão, volume e/ou quantidade. Nessa mesma linha de raciocínio, considera-se o crescimento econômico como o aumento da capacidade produtiva e da produção de uma economia, em determinado período de tempo. Normalmente é medido pela variação do PNB (Produto Nacional Bruto): soma de todos os bens produzidos e serviços realizados enquanto atividades produtivas de uma nação, independente do território onde foram produzidos, ou do PIB (Produto Interno Bruto): valor agregado de todos os bens e serviços finais produzidos dentro de um país, independente da nacionalidade das unidades produtivas.

Já o desenvolvimento econômico é um processo de mudanças sociais e econômicas que ocorrem numa determinada região. Considerando que a abrangência dessas mudanças envolve uma séria de inter-relações com outros elementos e estruturas presentes nessa região, configurando um complexo sistema de interações e abordagens, é um conceito mais qualitativo, incluindo as alterações da composição do produto e a alocação dos recursos pelos diferentes setores da economia, de forma a melhorar os indicadores de bem-estar econômico e social (pobreza, desemprego, desigualdade, condições de saúde, nutrição, moradia e educação) (SIEDENBERG, 2006).

\section{PROCEDIMENTOS METODOLÓGICOS}

Este estudo baseou-se em uma pesquisa descritiva exploratória, formulada a partir de materiais já elaborados, que permitiram obter informações sobre o tema analisado. Segundo Gil (2000, p. 44) "Pesquisas exploratórias têm como principal finalidade 
desenvolver, esclarecer, e modificar conceitos e ideias, com vistas na formulação de problemas mais precisos ou hipóteses pesquisáveis para estudos posteriores".

A técnica de pesquisa utilizada foi a pesquisa qualitativa, como forma de coletar uma percepção mais aprofundada dos entrevistados, desenvolvendo conceitos, ideias e entendimentos a partir de padrões encontrados nas entrevistas. Esta condição permite um "[...] refinamento bastante grande com relação à coleta bruta de dados à análise de sua representatividade no universo que forma o objeto da pesquisa. Esta forma de análise contribui para a qualificação da pesquisa e suas conclusões." (BORBA et al, 2004, p. 54 - 55).

A coleta de dados para este estudo foi realizada por meio de entrevistas, que permite ao investigador se apresentar ao investigado e lhe formular perguntas, por meio de um roteiro semiestruturado, com o objetivo de obtenção dos dados que interessam à investigação (GIL, 2009). As entrevistas foram realizadas in loco pelos pesquisadores no período de outubro de dois mil e dezesseis e foram aplicadas ao Gerente da Cooperativa Sulcredi-Ouro e à produtores rurais, tendo assim uma amostra não probabilística intencional.

Considera-se que a amostragem não probabilística utiliza critérios e julgamentos estabelecido pelo pesquisador como forma de obtenção de uma amostragem representativa. Conforme exposto por Costa Neto (1977, p. 264), “uma amostra não probabilística deriva-se da inacessibilidade a toda a população. Quando esta situação ocorre o pesquisador é forçado a colher a amostra na parte da população que lhe é acessível."

Com base nesses critérios pode-se atender aos objetivos determinados e saber qual o papel que a cooperativa de crédito Sulcredi Ouro tem no desenvolvimento da agricultura familiar presente na região.

\section{DESCRIÇÃO E ANÁLISE DE DADOS}

Neste tópico de estudo é apresentado um contexto histórico da cooperativa Sulcredi Ouro, os benefícios propostos, quais são os recursos próprios e de terceiros disponibilizados, volume de crédito, a relação entre cooperativa e agricultura.

Inicialmente, solicitou-se aos produtores que contassem um pouco da história da propriedade, sua trajetória e na sequência aspectos relacionados à cooperativa e o crédito agropecuário, como conheceram a cooperativa, motivos por fazer movimentações financeiras na cooperativa, a relação entre agricultura e cooperativa e os benefícios percebidos. 
As entrevistas com os produtores tiveram duração aproximada de 1 hora cada, realizadas por meio de uma abordagem formal e pautadas em uma conduta ética do pesquisador, onde as perguntas aos agricultores foram respondidas sem qualquer constrangimento e gravadas com o consentimento de todos.

Destaca-se que, as entrevistas com os produtores foram agendadas pelo gerente da Sulcrei Ouro, porém, no momento da abordagem, na propriedade rural, os produtores e seus familiares estavam desenvolvendo suas atividades laborais e, em alguns casos, era preciso aguardar a finalização. Não raras vezes, também, as entrevistas foram interrompidas para que o produtor pudesse desenvolver alguma atividade mais pontual. Diante ao exposto, não percebeu-se qualquer prejuízo ao mérito da pesquisa, mas sim, o fato da liberdade dada aos entrevistados para não prejudicar sua rotina de trabalho, pode ter promovido uma credibilidade do entrevistado perante ao produtor, culminando em uma participação sincera e solidária.

As propriedades rurais visitadas caracterizam-se como integrantes da agricultura familiar, com aproximadamente 18 hectares, onde são desenvolvidas diversas atividades produtivas, caracterizando assim a pluriatividade, corroborando o exposto pela revisão. Porém, a busca por crédito agrícola deu-se para otimização de atividades específicas.

Para contextualização, as produções de destaque em cada propriedade foram identificadas como: agroindústria de laticínios; olericultura, com produção baseada em alface, uva, morango, amora, maçã, ameixa, tomate, caqui; produção de animais, com destaque para avicultura. A opção por visitar estas propriedades deu-se pelo fato dos recursos do crédito agrícola serem solicitados para diferentes atividades produtivas, o que demandou linhas de crédito específicas, resultando em uma amostra (intencional) mais condizente com realidade atendida pela Sulcredi Ouro.

\subsection{Histórico da Cooperativa Sulcredi Ouro}

De acordo com informações do site da cooperativa e com as informações coletadas com as entrevistas, a constituição da Cooperativa de Ouro teve inicio em 2002, através de um plano de viabilidade para implantação de uma cooperativa de crédito no município de Ouro - SC, baseado na confiabilidade repassada pelo trabalho desenvolvido, foi 
lançado a Cooperativa de Crédito Rural com Interação Solidária de Ouro - Cresol Ouro, a qual veio a viabilizar créditos aos agricultores e suas famílias.

Sua história remonta ao ano de 2004, quando o sistema Cresol sofreu uma cisão do sistema através da criação de uma nova central de serviços - CRESOL CENTRAL, com sede em Chapecó - SC. A partir de junho do mesmo ano, com auxílio da Cresol Base Litoral, o plano de viabilidade foi apresentado e aprovado pela população do município. Em 2006, a cooperativa contava com 22 associados, com um volume de dinheiro de $\mathrm{R} \$ 200,00$ reais cada, totalizando um montante de $\mathrm{R} \$ 4.400,00$.

Em 17 de dezembro de 2005, o BACEN anunciou no Diário Oficial da União a constituição da Cresol Ouro e em 20 de dezembro de 2005 foi realizada a $1^{\text {a }}$ AGO Assembleia Geral Ordinária para constituição da cooperativa e aprovação do estatuto social. Na oportunidade foi constituído o $1^{\circ}$ Conselho de Administração e $1^{\circ}$ Conselho Fiscal, constituídos por 13 membros cooperados.

Em 2007, a Cresol Ouro deu um salto no fortalecimento do seu capital social, através do convênio com o BNDES para financiamento da cota capital a seus cooperados, aumentando significativamente seu patrimônio líquido. No mesmo ano foi firmado o primeiro convênio habitacional, através do Programa Social de Habitação e também convênio com o BRDE na linha de Pronaf Investimento.

Em 2009, a Cresol Ouro realizou a abertura de PACs nos municípios de Zortéa, Água Doce e Lacerdópolis. Realizando também o lançamento de dois produtos: uma linha diversificada de seguros e o cartão Cresol com bandeira própria.

Em 2014 o Sistema Cresol foi desfiliado. Na atualidade, a cooperativa de Ouro passa a integrar a rede Sulcredi, possuindo 3.500 associados, com um capital de $\mathrm{R} \$ 40$ milhões de reais, que trabalha visando atender os cooperados viabilizando linhas de crédito, valorizando o agricultor familiar e também os trabalhadores urbanos. A cooperativa possui ainda a missão de impulsionar o desenvolvimento local sustentável do campo e da cidade, trilhando seu caminho para que juntos todos possam trabalhar para construir, cada vez mais, uma "Cooperativa forte e que atenda as expectativas e necessidades de todos" (SULCREDI, 2016).

Quanto a opção pelos entrevistados em tornar-se cooperados da Sulcredi, os agricultores comentam que o fator motivador foi o relacionamento com o presidente da cooperativa, senhor Irineu Caetano Lovatel. A fala comum é que a opção se deu pelo fato dos 
produtores e o gerente da cooperativa serem amigos de longa data e que, quando a instituição estava sendo implantada no local, receberam um convite pessoal do presidente para integrar o quadro de cooperados. Reforçando a percepção do relacionamento com o fundador da Sulcredi no local ser fator de decisão para se tornarem cooperados da instituição, cita-se que o presidente da cooperativa exercia, anteriormente, atividades de presidente do sindicato rural, o que facilitou o contato e a adesão dos produtores.

Destaca-se também, conforme percebido nas entrevistas, que os produtores sentem orgulho de fazer parte da instituição desde o seu inicio, estando presente na história da cooperativa. Esta relação de amizade, em muitos casos auxilia nas suas movimentações financeiras voltadas para a cooperativa.

\subsection{Destinação dos recursos nas propriedades}

Dentre outros, os recursos do Pronaf podem ser utilizados na propriedade rural para custeio da produção, seguros, investimento na compra de equipamentos, animais ou mesmo estrutura física para otimização da produção. De acordo com os produtores entrevistados, o Pronaf é um recurso que possui juro baixo, um bom prazo para pagar e se for investido da forma correta, a propriedade consegue pagar o financiamento sem maiores dificuldades.

É percebido que as demandas por financiamentos nas propriedades rurais foram motivadas pelo mercado. Em um dos casos, na indústria de laticínios, no contexto histórico, a propriedade focava na produção de frangos e a atividade leiteira era secundária. A demanda forçou a especialização desta atividade, o que demandou investimentos na estrutura física para adequação à legislação para produção de alimentos. A primeira busca de recursos foi utilizada na propriedade para implantação da agroindústria, que na atualidade comercializa seus produtos somente no município de Ouro, pelo fato de ter somente o selo de inspeção municipal, o que não habilita a propriedade a comercializar seus produtos fora do município. A segunda busca de recursos do Pronaf pela propriedade deu-se como forma de ampliar a área de atuação. Os recursos estão sendo investido em melhorias e ampliações para obtenção do selo de inspeção estadual, o que habilita a propriedade a comercializar seus produtos em todo o território do estado de Santa Catarina. 
A propriedade que tem sua produção voltada para a olericultura demonstra uma relação de demanda do mercado diretamente relacionada com a cooperativa Sulcredi. Na atualidade, estão se estruturando para atender redes de fast food, sendo que este cliente foi indicação de colaboradores da cooperativa. A partir da demanda, o produtor buscou financiamento para investimentos em máquinas e equipamentos necessários ao processo produtivo.

A terceira propriedade visitada possui destaque para a produção de animais. No local, os recursos foram demandados para adequações e reformas dos aviários, principal atividade, e na atualidade estão sendo realizados investimentos para produção de gado bovino no sistema free stall.

Uma informação a ser destacada é que em duas das propriedades visitadas era desenvolvida anteriormente, como atividade produtiva, a produção de frangos. Na atualidade, a produção avícola não é mais desenvolvida, que teve a produção de laticínios e a olericultura desenvolvida como alternativa a avicultura. Na terceira propriedade, a produção de aves é amplamente desenvolvida, porém, o proprietário busca alternativas para diversificação e otimização dos ganhos.

Em todos os casos, porém, para aquisição dos recursos os agricultores demonstram a necessidade do crédito e percebem na cooperativa Sulcredi Ouro uma fonte de informações e de auxílio. São unânimes em afirmar que a intermediação da cooperativa é essencial, e que esta é a primeira opção para busca de informações e aquisição dos recursos financeiros. Destacam também que a cooperativa dá suporte na opção pela melhor linha de financiamento, elaboração do projeto e na avaliação. Este suporte é desenvolvido também como forma de otimizar o processo pois, estando o projeto dentro das normas da cooperativa e dos parâmetros do agente financiador, é liberado o crédito.

Em síntese, os investimentos nas propriedades rurais realizados para a compra de insumos para o processo produtivo, desenvolvimento da agroindústria familiar, maquinas, equipamentos, avicultura, sendo que todos esses investimentos se utilizados da forma correta trazem retornos positivos para os agricultores, como percebido na fala dos entrevistados, para a Sulcredi Ouro e para o desenvolvimento econômico da região, corroborando o exposto na revisão bibliográfica.

Novamente destaca-se a questão do relacionamento do produtor rural com a cooperativa Sulcredi Ouro como fator de decisão para captação de recursos do Pronaf. De 
acordo entrevistados, percebida a demanda, a cooperativa é a primeira opção de informações e, parafraseando um dos entrevistados, precisando de alguma coisa "eles", a Sulcredi, estão sempre a disposição, desde a parte de atendimento, auxilio, orientação, até o suporte.

\subsection{Benefícios propostos pela Cooperativa Sulcredi Ouro}

A cooperativa Sulcredi Ouro dispõe de alguns benefícios que contribuem para o desenvolvimento da agricultura familiar, dentre eles, destacam-se taxas de juros subsidiadas, facilidade no atendimento, baixo custo de manutenção da conta (tarifas), desburocratização do crédito, os lucros obtidos são investidos na região e divididos entre os associados, auxílio na gestão da propriedade.

Os entrevistados consideram uma relação de união com a cooperativa e se orgulham de fazer parte da história da instituição no município. Esta condição é percebida ao longo das entrevistas ao citarem que, a cooperativa, quando iniciou possuía 20 agricultores, sendo propriedades pequenas, mas com um bom solo para produzir, desde o início até hoje a cooperativa buscou dar apoio ao desenvolvimento da agricultura, disponibilizando recursos para custeio, investimento e também fazendo um acompanhamento no processo.

De acordo com os agricultores a cooperativa auxilia nos projetos, faz acompanhamentos, indica as melhores linhas de financiamento. Além do básico, a cooperativa tem o envolvimento pessoal, que busca de uma forma ou outra ajudar os agricultores, um exemplo disso, foi a indicação realizada por uma funcionária que recebeu uma visita de um técnico da empresa Refricon que fornece alface americana para o Mc Donalds, Subway, Bob’s, Burguer King.

A relação da cooperativa com a comunidade tem impacto direto no desenvolvimento econômico do local. Como justificativa a esta afirmação, considera-se que a intermediação dos recursos financeiros disponibilizados permite a geração de renda e a manutenção das famílias no campo.

$\mathrm{Na}$ agroindústria de produtos laticínios, esta condição fica mais evidente pois, com a matéria prima é coletada na comunidade, em seis pequenas propriedades rurais. De acordo com os entrevistados, $50 \%$ do leite utilizado no processo produtivo é produzido na propriedade e os demais são coletados nos vizinhos, todos pequenos produtores, que segundo informações dos entrevistados, não teriam condições de se tornarem competitivos ou 
fornecedores de grandes agroindústrias devido ao baixo volume de produção. No total, a agroindústria gera renda para oito famílias.

Na propriedade que explora a olericultura, esta condição também é percebida, porém gerando um benefício no meio urbano do município de Ouro, pois a mão de obra, por ser mais pontual, é buscada na cidade. O produtor não soube quantificar o número de funcionários necessários por não ter ainda uma regularidade, porém, por observação, quantificou-se 5 trabalhadores, além dos integrantes do grupo familiar, exercendo atividades no momento da entrevista.

$\mathrm{Na}$ terceira propriedade visitada, a entrevista foi realizada no momento em que estava sendo feito o carregamento dos frangos. Assim, foi percebida a movimentação de trabalhadores no local. Para esta atividade, foram necessários motoristas e equipes de carregadores, além do grupo familiar, podendo-se considerar que os investimentos realizados na propriedade movimentam toda uma cadeia produtiva a montante do processo de terminação dos frangos. Salienta-se que diretamente, na propriedade, duas famílias exercem atividades no processo produtivo.

Além da geração de empregos diretos, pode-se considerar que a relação com o desenvolvimento econômico se dá no comércio de produtos e serviços destinados à atividade rural, pois os produtores adquirem insumos e recursos na região, movimentando o comércio e a indústria local, reforçando positivamente o exposto pela revisão bibliográfica realizada.

\subsection{Volume de crédito dos recursos próprios e de terceiros disponibilizados}

A cooperativa Sulcredi possui uma carteira total de recursos próprios e recursos especiais de R\$ 39 milhões, da cota capital de 100\%, 60\% é utilizado em aplicação (poupança) e $40 \%$ saldo da conta corrente.

Cerca de $20 \%$ da carteira total é disponibilizado aos agricultores, destinados ao custeio da lavoura, pecuária, compra de gado, máquinas e equipamentos, plantio de pastagem, hortifruti, agroindústria familiar.

Para obter o crédito na cooperativa o agricultor deve possuir um projeto comunicando a necessidade do crédito, após isso a cooperativa analisa a proposta, faz a verificação se o projeto se encaixa nas normas da cooperativa e também busca fazer uma 
visita na propriedade do agricultor para verificar se possui a necessidade do crédito e, posteriormente, a liberação do projeto.

A cooperativa Sulcredi Ouro faz intermediações com o governo federal para arrecadar dinheiro, repassando todo o volume de crédito que o governo disponibiliza aos agricultores, isso se torna para a cooperativa uma vantagem.

Com relação aos recursos de terceiros, repassados aos agricultores cooperados, a cooperativa busca parcerias com alguns bancos, dentre eles, a Caixa Econômica Federal, o Bradesco, Bicbanco, Banco Safra, BRDE, e também possui um convênio com o Banco Do Brasil, sendo mais utilizado para o custeio da agricultura.

\section{CONSIDERAÇÕES FINAIS}

A agricultura familiar é reconhecida pela sua importância em gerar empregos no campo e por produzir alimentos para suprir as necessidades de consumo da população, como ferramenta de desenvolvimento econômico, diversificação da produção econômica e para manter os indivíduos no meio rural.

Sobre esse aspecto, considera-se que a cooperativa Sulcredi Ouro desempenha papel fundamental na busca por melhores condições de trabalho, produtividade e aumento da renda dos agricultores. Estes fatores servem de estimulo a população rural, evitando a migração da população rural para a zona urbana das cidades.

A cooperativa de crédito atua fazendo com os recursos cheguem de forma ágil e prática ao agricultor familiar, contribuindo assim para o desenvolvimento da região, que tem sua economia baseada na agricultura. $\mathrm{O}$ crédito permite ao agricultor familiar ampliar suas relações com o ambiente socioeconômico, agregando os avanços tecnológicos, beneficiandose da assistência técnica, movimentando o comércio e serviços da cidade, seja na medida da compra de seus insumos para a produção ou na venda de seus produtos.

Por meio da análise das entrevistas e da revisão bibliográfica, pode responder à pergunta norteadora do estudo, atendendo ao objetivo geral, uma vez que fica caracterizada a cooperativa Sulcredi Ouro, não somente como promotora da agricultura familiar da região, mas em especial promovendo ações que oportunizam o acesso dos pequenos agricultores familiares à programas e fundos de nível nacional, ao mesmo tempo em que presta auxílio na estruturação, quantificação, projeção melhoria e implantação das melhoras nas propriedades 
rurais familiares. Em especial percebe-se a utilização dos recursos oriundos das ações originadas, ou intermediadas pela Sulcredi, na aquisição de insumos e ampliação das atividades desenvolvidas nas propriedades, e em alguns casos, a mudança e diversificação do produzido pelos cooperados.

O investimento na propriedade proporciona uma série de benefícios para o agricultor familiar, pois além de trazer melhorias para a propriedade, contribui para o desenvolvimento econômico que se caracteriza pelo aumento da produtividade ou da renda. Os bens adquiridos contribuem para o desenvolvimento da economia local, por que dependem e precisam dos serviços de manutenção, insumos, combustíveis, entre outros itens para o funcionamento, gerando assim um movimento na economia local.

\section{REFERÊNCIAS}

BORBA, J.T.; BOCCHI, J.A.; AGUERO, P.H.V.; MACEDO, Z.L. Monografia para economia: São Paulo. Saraiva, 2004.

BRUndTLAND, Comissão. Comissão Mundial sobre Meio Ambiente e Desenvolvimento: o nosso futuro comum. Universidade de Oxford. Nova Iorque, 1987.

BÚRIGO, F.L. Finanças e Solidariedade cooperativismo de crédito rural solidário no Brasil. Chapecó: Argos, 2010. 454p.

CARMO, M. S. do. A Produção Familiar como Locus Ideal da Agricultura Sustentável. Agricultura em São Paulo, São Paulo, v.45, n.1, p.1-15, 1998.

COSTA NETO, P. L. O. Estatística. São Paulo: Edgard Blücher, p. 264. 1977.

DIAS, J.; DIAS, M. H. A. Crescimento Econômico e as Políticas de Distribuição de Renda e Investimento em Educação nos Estados Brasileiros: Teoria e Análise Econométrica. Porto Alegre: Anpec Sul: UEM, 2005.

FRANKE, W. Influência rochdaleana na legislação cooperativista brasileira e problemas atuais. In: FRANKE, W., FARIA, G. E. e PÉRIUS, V. F. et al. A interferência estatal nas cooperativas. Porto Alegre: Fabris, cap. 1, p. 9-24. 1988.

GIL, A. C. Como elaborar projetos de pesquisa. Métodos e Técnicas de Pesquisa Social. 4. ed. São Paulo: Atlas, 2009.

GIL, A. C. Técnicas de pesquisa em economia e elaboração de Projetos e monografias: São Paulo: Editora Atlas, 2000. 
GRISA, C. As políticas para a agricultura familiar no Brasil: um ensaio a partir da abordagem cognitiva. Desenvolvimento em Debate. Rio de Janeiro, v. 1, n. 2, p. 83-109, 2010.

JOHNSTON, B. F.; MELLOR, J. W.The role of agriculture in economic development. The American Economic Review, v. 51, n. 4, p. 566-593, 1961.

JONES, C.I. Introdução à Teoria do Crescimento Econômico. Rio de Janeiro: Campus, 2000 .

LAMARCHE, H. A Agricultura Familiar. Campinas, ed. Unicamp, São Paulo, 1993.

MENDES.E.P.P.; MESQUITA. A.P. Agricultura Familiar, trabalho e estratégias: a participação feminina na reprodução socioeconômica e cultural. Espaço em Revista, Universidade Federal de Goiás, GO, vol. 14, n. 1, jan./jun, p. 14-23 2012.

OLIVEIRA, J. T. A de. Breve História do trabalho Rural no Brasil. Campinas, SP: Faculdade de Engenharia Agrícola, 2009. Disponível em: <www.feagri.unicamp.br>.Acesso em 07 maio de 2016.

PADILHA, W.; MEDEIROS, M. C. As mudanças recentes no credito rural e a dinâmica regional da agricultura brasileira. In: Anais do XVI Encontro Nacional de Geógrafos: crise, práxis e autonomia: espaços de resistências e de esperanças. Porto Alegre-RS, 2010.

PEREIRA, S. E.; FIGUEIREDO, A. S.; LOUREIRO, P. R.A. Avaliação do impacto da utilização de crédito, da educação e da escolha do canal de comercialização na horticultura: caso do núcleo rural do Distrito Federal. Revista da SOBER, v. 44, n 4, 2006.

PINHEIRO, M. A. H. Cooperativas de Crédito: História da evolução normativa no Brasil. 5. ed. Brasília: BCB, p.94. 2007.

PIRES, M. L. L. e S. et al. Cooperativismo, agricultura familiar e redes sociais na reconfiguração dos espaços rurais. In: Congresso Brasileiro de Sociologia: consensos e controvérsia, 14, 28-31 jul. Rio de Janeiro, 2009.

SARON, F. A.; HESPANHOL, A. N. O PRONAF e as políticas de desenvolvimento rural no Brasil: o desafio da (re)construção das políticas de apoio a agricultura familiar. In: Revista Geo UERJ. Ano 14. v. 2. n. 23. p. 656-683. $2^{\circ}$ semestre. Rio de Janeiro-RJ, 2012.

SIEDENBERG, D. R. Dicionário do Desenvolvimento Regional. Santa Cruz: Edunisc, 2006.

SCHNEIDER, Sérgio. Teoria social, agricultura familiar e pluriatividade. Rev. bras. Ci. Soc., São Paulo, v. 18, n. 51, p. 99-122, Feb. 2003.

SULCREDI. Cooperativa de crédito rural. Ouro, SC, 2016. Disponível em $:<$ http://www.sulcredi.com.br/pagina.php?id=22>. Acesso em 13 de out. de 2016. 